\title{
Fire on the mountain: A multi-scale, multi- proxy assessment of the resilience of cool temperate rainforest to fire in Victoria's Central Highlands
}

\section{Patrick J. Baker}

School of Biological Sciences, Monash University, Clayton, Victoria patrick.baker@monash.edu

\section{Rohan Simkin}

Monash University, Clayton, Victoria

\section{Nina Pappas}

Monash University, Clayton, Victoria

\author{
Alex McLeod \\ Monash University, Clayton, Victoria \\ Merna McKenzie \\ Monash University, Clayton, Victoria
}

\section{Introduction}

A common feature of many Australian landscapes is the interdigitation of eucalyptdominated sclerophyll forest with rainforest. In most instances, the eucalypt forests dominate the landscape, with rainforest restricted to relatively small fragments and strips that are often (but not always) associated with topographic features such as riparian zones or southeasternfacing slopes. However, these patterns reflect the current state of a dynamic system. Over several 
hundreds of thousands of years, the relative dominance of the rainforests and eucalypt forests has waxed and waned across these landscapes in near synchrony (Kershaw et al.2002; Sniderman et al. 2009). During periods of relatively warm, dry conditions, the eucalyptdominated vegetation has expanded and the rainforest contracted across the landscape. When the climate has been relatively cool and moist, the rainforests have expanded and the eucalypt forest contracted. This is, in part, thought to be a direct consequence of the ambient environmental conditions and their impact on regeneration success. However, the indirect influence of climate, in particular as a driver of fire regimes, may be as important, if not more important, in defining the structure, composition and relative abundance of rainforest and eucalypt taxa at the landscape scale. During warmer, drier periods fires occur more frequently or are more severe, whereas during cooler, wetter periods the opposite holds (Kershaw et al. 2002). Because rainforest and eucalypt species are considered to be fire-sensitive and fire-resilient, respectively, periods of more frequent or more intense fires should favour the expansion of eucalypt forests and the retreat of rainforests.

Much of the palaeoecological research examining the historical variability of climatefire interactions and their role in modifying plant community composition has focused on very long time scales - typically millennia or longer. However, these patterns in long-term vegetation dynamics are driven by the accumulation of events that occur on much shorter time scales (i.e. annual to decadal) - scales that are relevant to management and conservation. In an attempt to link this ecological time scale with the longer-term patterns in vegetation dynamics in a temperate Australian context, Jackson (1968) proposed a probabilistic model that related forest composition - in particular, the relative abundance of rainforest and eucalypt species - to fire frequency. He suggested that where fire return intervals were $<50$ years, the vegetation would shift towards communities dominated by grasses and shrubs. In contrast, where fire return intervals were $>350$ years, the vegetation would be dominated by rainforest species. At fire return intervals between these thresholds, Jackson hypothesised that mixed forest dominated by eucalypts should persist. A key assumption of Jackson's model is that rainforest tree species are both sensitive to fire and lack resilience to fire. Thus, in the presence of fire return intervals of less than approximately 300 years, rainforest species have a low probability of persistence within a landscape. Although Jackson developed these ideas for Tasmanian forests, his conceptual model has been widely applied to other Australian landscapes where rainforest and eucalypt forest occur together (e.g. Noble and Slatyer 1980; Ash 1988; Unwin 1989; Bowman 2000) and is commonly used to describe the relationship between eucalypt and rainforest communities to the general public (Figure 1).

In the complex mountainous terrain of Victoria's Central Highlands, areas of cool temperate rainforest dominated by Nothofaguscunninghamii (myrtle beech) and Atherosperma moschatum (southern sassafras) occur along headwater streams within a landscape matrix of tall open forest dominated by Eucalyptus regnans (mountain ash) and E. delegatensis (alpine ash). One of the most striking features of the ecology of these tall open forests is the degree to which their dynamics are driven by catastrophic fires. The tall open forests of southeastern Victoria and Tasmania are subject to intense crown fires, which kill a large proportion of the trees over tens or hundreds of thousands of hectares in a single event. The energy released in these fires can be extraordinary, with fireline intensities commonly exceeding $100,000 \mathrm{~kW} \mathrm{~m}^{-1}$. The eucalypts in these forests are well adapted to this type of fire regime and release seed stored in their crowns soon after a fire passes. The high light environment and heat-treated surface soils promote quick germination and vigorous growth of the new seedlings. This leads to dense, fast-growing stands of tall mountain and alpine ash and is the ecological basis of the clear-fell, burn and sow (CBS) silvicultural 


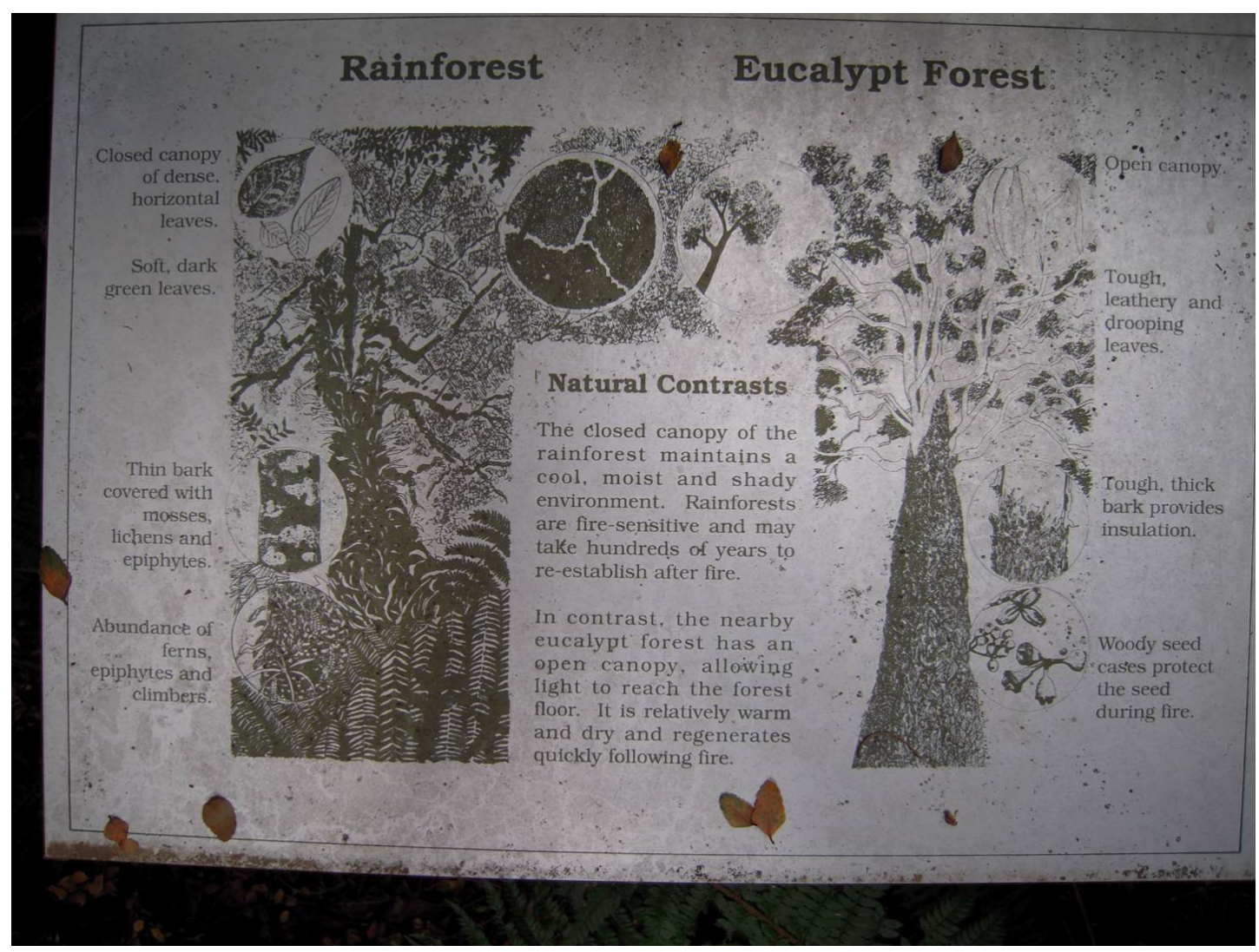

Figure 1. Interpretive signpost along a hiking trail in cool temperate rainforest near Marysville in the Central Highlands, Victoria. One of the stated 'Natural Contrasts' between the rainforest and the eucalypt forest is that 'rainforests are fire-sensitive and may take hundreds of years to re-establish after fire'. The rainforest immediately adjacent to the trail survived the 2009 fires; all Eucalyptus regnans trees within $100 \mathrm{~m}$ of the sign were killed by the fires.

system that is widely applied in the tall open forests of the Central Highlands (Attiwill 1994).

Fires are as much a part of the Central Highlands and the surrounding areas as the flora and fauna. In most years, fires occur somewhere within these landscapes. However, since European settlement, three fire seasons have stood out from the rest in terms of extent, ferocity and damage: 1851, 1939 and 2009. Each of these fires was preceded by a period of prolonged high temperature and low relative humidity; each was fanned by hot, dry winds from the arid centre of the continent; and each led to substantial loss of human life and property. From an ecological perspective, each of these fires led to widespread mortality of the forest canopy over hundreds of thousands of hectares and a subsequent landscape-wide pulse of regeneration. Given that the time between these fires was 88 years and 70 years, Jackson's model would suggest that the landscape would be predominantly eucalypt forest and that rainforest taxa would be severely disadvantaged. However, in the wake of the 2009 fires, it was evident that large tracts of cool temperate rainforest in areas subjected to high-intensity crown fires had survived more or less intact (Pappas 2010). In some instances, cool temperate rainforest stands that survived the 2009 fires were also known to have survived the 1939 and 1851 fires (Simkin and Baker 2008). If cool temperate rainforest is as fire-sensitive as widely believed, this presents a significant conundrum and seems to run counter to Jackson's model of fire frequency and forest composition. More fundamentally, it raises a simple question: How does cool temperate rainforest in the Central Highlands respond to fire? There are two key issues that must be addressed in answering this question. The first is the temporal scale of enquiry; the second is the distinction between the history of fire and the history of rainforest species on the landscape. Recent work by Whitlock et al. $(2003,2004)$ has highlighted the strength of using a multiproxy approach to deal with these issues simultaneously. 


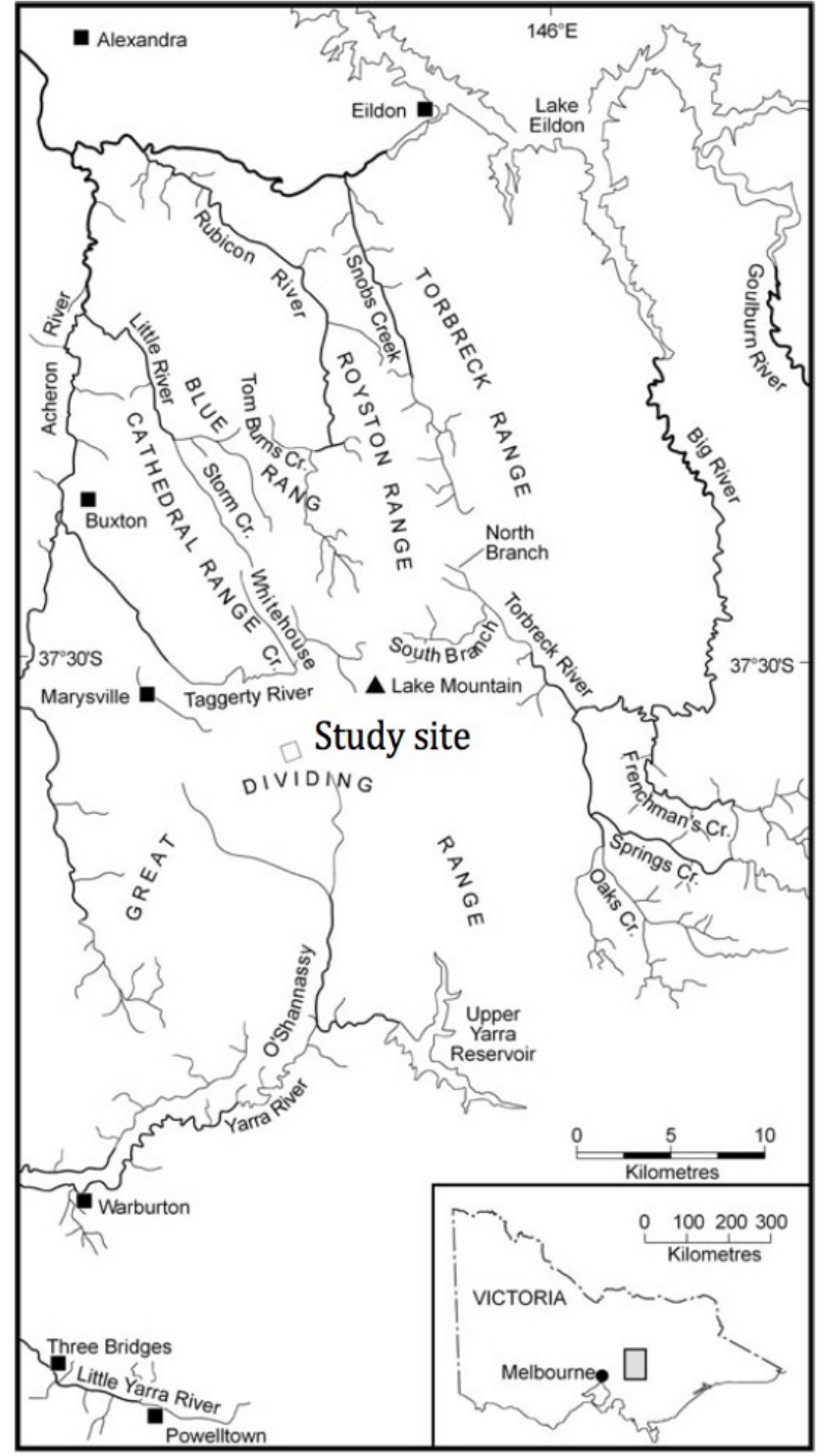

Figure 2. Location of the Bellel Creek study site from which tree ring, pollen and soil charcoal samples were collected. After McLeod (2007).
Fire ecology in southeastern Australia has benefited from research across a range of temporal and spatial scales, but much of it has focused on either direct observation and experimental manipulation or on proxy records. Inferences from these data are at very different time scales. Direct observations are relevant at annual to decadal scales, whereas most of the proxy data are relevant at the scale of millennia or tens of millennia. A multi-proxy approach allows us to bridge this scale gap and to differentiate between the history of fire and the history of rainforest. For example, soil charcoal provides data on fire occurrence, while pollen records provide data on the rainforest occurrence. Tree rings provide insights into the response (i.e. survival and recruitment) of rainforest species to specific, known fire events, while direct observations provide insights into the scale and severity of fires on rainforest, and their immediate response. The greatest impediment to this multi-proxy approach in Australia has been the lack of multiple proxies from the same area. In this chapter, we take advantage of a unique collection of proxy data sets collected from a single site, Bellel Creek, near

Lake Mountain in the Central Highlands of Victoria (Figure 2), as well as other proxy data sets from southeastern Australia that provide additional local and regional context. Together with direct observations from the 2009 Victorian bushfires, we use them to critically examine the resilience of cool temperate rainforest to fire across a wide range of time scales (e.g. decadal to millennial).

\section{Cool temperate rainforest and fire}

\section{Evidence from direct observations}

In Australian plant ecology, it is almost axiomatic that rainforests are highly sensitive to fire and that rainforest tree species lack the ability to survive all but the lowest intensity fires (e.g. Jackson 1968; Noble and Slatyer 1980; Busby and Brown 1994; Bowman 2000, Figure 1). Nonetheless, the empirical evidence for these assertions is surprisingly weak and is confounded by vague or inconsistent definitions of 'rainforest' and 'sensitivity' (Hill 2000). In a continent dominated by eucalypts and acacias, which are often highly adapted to fire, rainforest species are relatively poorly adapted to fire. However, their persistence on the landscape for hundreds 
of thousands of years suggests that they must have some inherent capacity to either survive fire or regenerate in the wake of fire.

In southeastern Australia, there are large tracts of forest dominated by tall eucalypts such as E. regnans and E. delegatensis in which the dominant disturbance regime is one of catastrophic crown fires (Ashton 2000). Yet within these landscapes, there exist areas of cool temperate rainforest that have obviously persisted for centuries, if not millennia. Howard (1973) described the distribution and ecology of cool temperate rainforest in Victoria's Central Highlands. She showed that rainforest species, such as $N$. cunninghamii and $A$. moschatum, were typically restricted to riparian areas and cool, moist gullies that were found in the broader landscape matrix dominated by tall eucalypt species. However, she did find areas - for example, near $\mathrm{Mt}$ Donna Buang - in which whole hillsides were dominated by rainforest. Similarly, Lindenmayer et al. (2000) found that while $N$. cunninghamii were commonly associated with cooler, wetter microclimatic conditions, individual trees were not restricted to these sites.

The long-term maintenance of areas of rainforest within these landscapes depends on the successful regeneration of rainforest species. Howard (1973) and Read and Hill (1985) have both suggested that seedlings of the relatively shade-tolerant $N$. cunninghamii could establish under closed canopy, but that successful regeneration was more often associated with gaps in the forest canopy. These studies provided the foundation for the widely held view that cool temperate rainforest is a self-replacing 'climax' vegetation type. As canopy trees in the rainforest senesce and die, they create small gaps in the forest canopy that allow new individuals of rainforest species to establish and, in the absence of exogenous disturbance, perpetuate the rainforest on that site. In reality, however, few, if any, areas that support cool temperate rainforest are free of exogenous disturbance. The landscape matrix of tall eucalypt forests in which they occur is susceptible to high-intensity crown fires, which are likely to impact on the patches and strips of rainforest that are scattered within this matrix.

There are two potential questions that directly bear on the issue of rainforest resilience to fire and for which direct observations may provide useful insights. First, do high-intensity, landscape-scale crown fires kill rainforest trees? And, second, if they do kill rainforest trees, do rainforest species regenerate or are they replaced by eucalypt species? Because catastrophic fire events are relatively rare, there are few studies addressing either question. Recently, Pappas (2010) has documented the impacts of the 2009 fires on rainforest located in areas of the Central Highlands north of Marysville that were among the most severely burned. The first and most obvious feature of the 2009 fires is that despite their extent and intensity, the resulting pattern of burn severity was highly variable (Figure 3). Across the broader landscape, some areas of forest were completely consumed (that is, all trees were killed and the leaves and small branches immolated), while others were much less severely impacted. Post-fire surveys of other large, catastrophic fire events (e.g. 1988 Yellowstone fires, 2002 Oregon Biscuit fire) have shown that fire impacts and the resulting re-establishment of vegetation are highly heterogeneous across a range of spatial scales (Kashian et al. 2004; Schoennagel et al. 2008; Donato et al. 2009). In the cool temperate rainforests that Pappas (2010) studied, fire impacts ranged from complete stand-level mortality to small patch burns of $<100 \mathrm{~m}^{2}$ to areas that showed no evidence of fire impacts. Indeed, the most striking finding of the survey was the variability in fire impacts on rainforest, particularly given that in nearly every case adjacent stands of $E$. regnans and $E$. delegatensis suffered complete crown loss and mortality - in many cases, right up to the margins of the rainforest. So, cool temperate rainforest does appear to be relatively resilient to intense fires within the landscape. In part, this may be explained by the wetter, cooler microclimatic conditions of the riparian zones where the largest rainforest patches are found. However, the close proximity of fire-killed eucalypts to the rainforest margin (often $<20 \mathrm{~m}$ ) suggests that topographic and microclimatic differences cannot alone explain the differential impacts of 
mortality between the areas of rainforest and eucalypt-dominated forest.

The other issue - do rainforest species regenerate in the wake of the fire - has also received little attention due to the relative rarity of large, catastrophic fires over the past century. In a survey of two fires in Tasmania in the early 1980s, Hill and Read (1984) observed that in an area of rainforest that was burned, there was abundant rainforest regeneration (from both seed and sprout) - and no indication of eucalypt incursion. However, in an area of mixed forest, where the mature individuals of rainforest species were less abundant and there was a eucalypt overstorey, the regeneration was dominated by eucalypts. Pappas (2010) found that seedlings and vegetative sprouts of $N$. cunninghamii occur in fire-induced gaps in rainforest within 18 months of the 2009 fires; however, their distribution was highly patchy. In addition, she found that eucalypt regeneration was limited to the ecotones between the rainforest patches and the surrounding eucalypt forest and that most of the woody regeneration from seed within the rainforest was from Acacia species (A. dealbata and A. frigrescens).

\section{Evidence from tree rings}

Tree rings are an important source of proxy data on past climatic conditions and ecological dynamics. The strict dating control on, and annual resolution of, tree-ring chronologies allow for accurate dating of past environmental conditions and ecological events (e.g. fires, windstorms) over several centuries, and in some cases, millennia. Tree rings have been used extensively in the northern temperate zone to study the interactions between climate variability, historical fire regimes and forest dynamics (e.g. recruitment, growth and mortality; Swetnam and Betancourt 1990; Swetnam 1993; Brown and Wu 2005). These studies have provided important insights into forest dynamics because they address the time scale of decades to centuries, which is intermediate to the shorter time scales of direct observation and the longer time scales of palaeoecological studies based on pollen and charcoal abundances in lake and ocean sediments. In Australia, where most tree species do not form annual growth rings, relatively few dendrochronological studies have been conducted, limiting inference at this intermediate time scale. The few treering studies that have been conducted in southeastern Australia have focused exclusively on

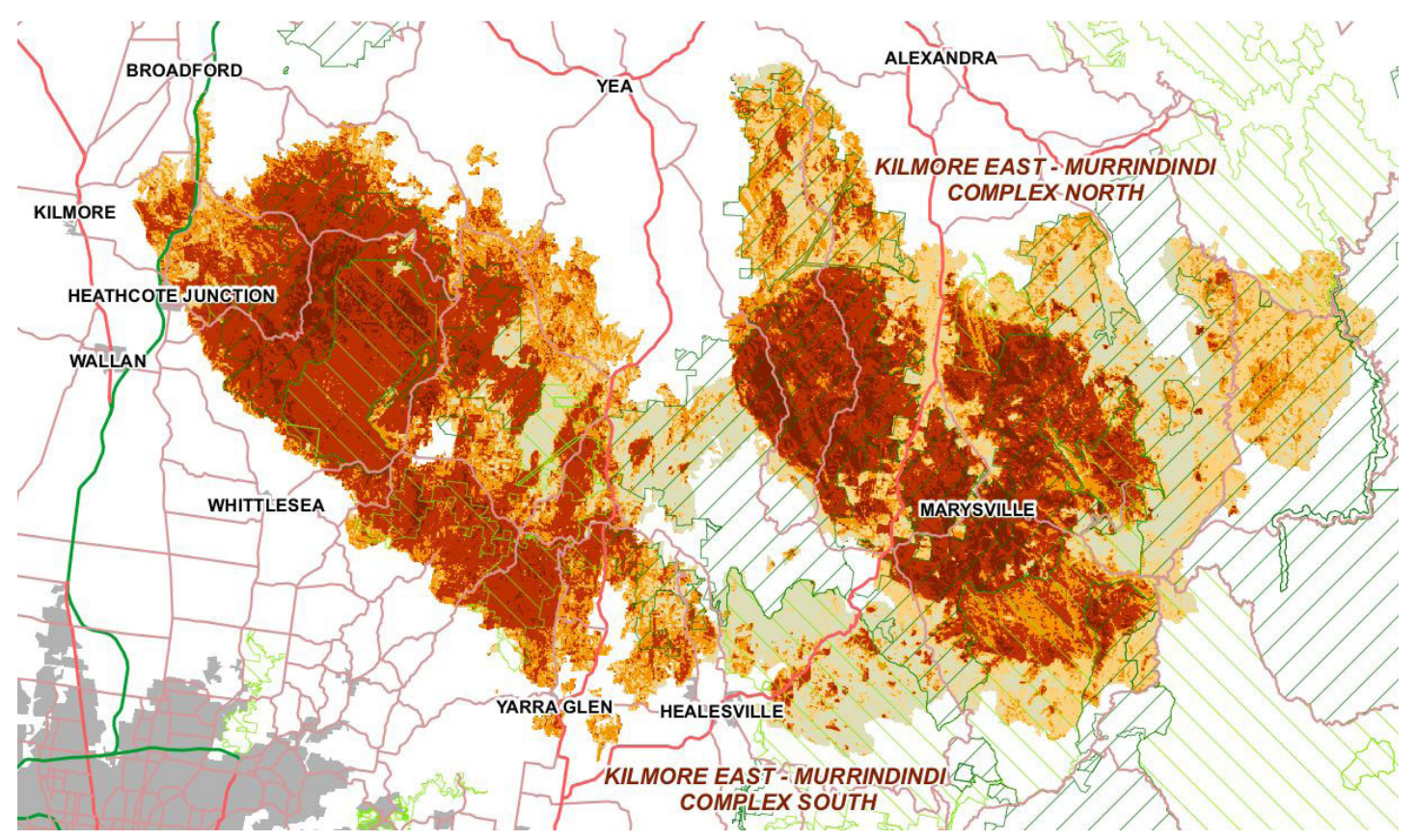

Figure 3. Variability in fire severity in the 2009 Kilmore-Murrindindi fire complex. Within the fire boundaries, darker colours represent more severe fires and lighter colours represent less severe fires. Map provided courtesy of the Department of Sustainability and Environment, Victoria. 
reconstructing historical climate variability using the long-lived conifers endemic to Tasmania (Cook et al. 1991; Allen et al. 2001, In press). The best example of this is the multi-millennial reconstruction of summer temperatures in western Tasmania that was developed from huon pine (Lagarastrobus franklinii ) (Cook et al. 1991, 2000).

Recently, however, Simkin and Baker (2008) used dendrochronological techniques to examine the role of fire on forest dynamics across an edaphic gradient in the Central Highlands of Victoria. Individual trees of several species were cored in rainforest along the riparian margins of Bellel Creek and in eucalypt forest on the mid slopes and upland sites away from the creek. The rainforest was dominated by Nothofagus cunninghamii and Atherosperma moschatum; the eucalypt forest was dominated by Eucalyptus regnans and E. delegatensis. The mid-storey tree species, Acacia dealbata, was common near the transition from rainforest to eucalypt forest and in the eucalypt forest. Although $N$. cunninghamii is typically associated with riparian sites, it was relatively abundant in the mid storey of the eucalypt forest for several hundred metres away from Bellel Creek. Detailed statistical analyses of inventory plot data across the Central Highlands have shown that $N$. cunninghamii is not strictly limited to wet sites and in some instances has been found in dry sites on relatively exposed ridges (Lindenmayer et al. 2000).

The reconstructed age distributions and growth patterns derived from the tree-ring samples at Bellel Creek demonstrated that the 1939 bushfire had a dramatic impact on the mid-slope and upland sites dominated by eucalypts. In these areas, all of the sampled trees for all species on both sides of Bellel Creek had established in the years immediately after the fire. However, in the rainforest area, many of the trees that were alive at the time of sampling in 2006 were established well before the 1939 fires. Indeed, some individuals - mostly large, gnarled $N$. cunninghamii, many with old fire scars - were established more than 200 years before that fire (Simkin and Baker 2008), and thus may have also survived the other major bushfire that had swept through the Central Highlands in 1851.

The other finding of interest from these dendroecological analyses was that across all of the sites (i.e. riparian, mid slope and upland) there was a distinct pulse of $N$. cunninghamii recruitment immediately after the 1939 fire (Figure 4). Few studies have focused on the conditions that favour recruitment of rainforest species in southeastern Australia. Howard (1973) examined patterns of natural regeneration of $N$. cunninghamii and, in particular, in situ recruitment and the role of gap dynamics in creating the appropriate conditions for successful regeneration. Although a recruitment pulse in eucalypts and acacias is to be expected after a severe bushfire, only Hill and Read (1984) have previously noted (based on direct observation) that rainforest species are capable of vigorous regeneration after fire. However, at Bellel Creek, the reconstructed age distributions obtained from tree rings provide strong empirical evidence of widespread recruitment of $N$. cunninghamii, the dominant species of the rainforest canopy in these forests, in the wake of the 1939 fire (Simkin and Baker 2008). Howard (1973) provides some support for this in her earlier study of N. cunninghamii on Mt Donna Buang in the Central Highlands. She used ring counts (without cross-dating) of $N$. cunninghamii to age the canopy trees, and noted that they comprised a single age cohort of individuals that had established in it, which contradicts the idea that rainforest species such as $N$. cunningbamii occurring in the understorey or mid storey of mountain ash forests in some areas of the Central Highlands are the 'climax' species that will eventually replace the overstorey eucalypts as part of a relayfloristics-like succession (Jackson 1968; Howard 1973). Rather, the shorter N. cunninghamii established contemporaneously with the eucalypts, but due to differences in height growth rates and relative shade tolerance, have formed stratified, even-aged, mixed-species stands (see e.g. Oliver and Larson 1996). 


\section{Evidence from pollen}

Pollen records are a mainstay of palaeoecological research around the world. In southeastern Australia, they have provided important insights into the tempo and mode of climatic variability and the ensuing changes in vegetational composition during the late Quaternary, and in particular the Holocene, periods. However, the pollen record in southeastern Australia has several important limitations. First, because of the geomorphological history of the region, pollen records are relatively sparse, being restricted to either calderal lakes in the broad peneplains, or perched bogs or swamps in areas of more varied topography. Second, the weak intra-annual seasonality and substantial intra-decadal variability in climatic conditions mean that annual varving of sediments is weak or absent, limiting the temporal resolution of palaeoecological reconstructions for the region. Third, the substantial changes in land-use history over the past two centuries have compromised the quality of many potential palaeoecological sites due to physical mixing of the sediment profile (e.g. from livestock trampling).

Despite these limitations, palaeoecological reconstructions of vegetation in the Central Highlands have provided important insights into historical changes in the distribution and abundance of various plant taxa for at least the past 35,000 years. This has been achieved through the development and analysis of multiple pollen-based reconstructions, which have shown several common, and consistent, patterns. McKenzie $(1997,2002)$ used pollen and microcharcoal to develop the most comprehensive palaeoecological reconstruction of vegetation change in the Central Highlands. The pollen record compiled by McLeod (2007) from Bellel Creek offers a point of comparison with the other proxy records (i.e. tree rings, soil charcoal) developed from the same site. Interpretation of long-term variability in rainforest dynamics is based primarily on the presence of $N$. cunninghamii pollen in the sediment samples, which show that $N$. cunninghamii has been present within the Central Highlands landscape for most of the past 35,000 years. McKenzie (1997) notes the presence of $N$. cunninghamii in the basal portions

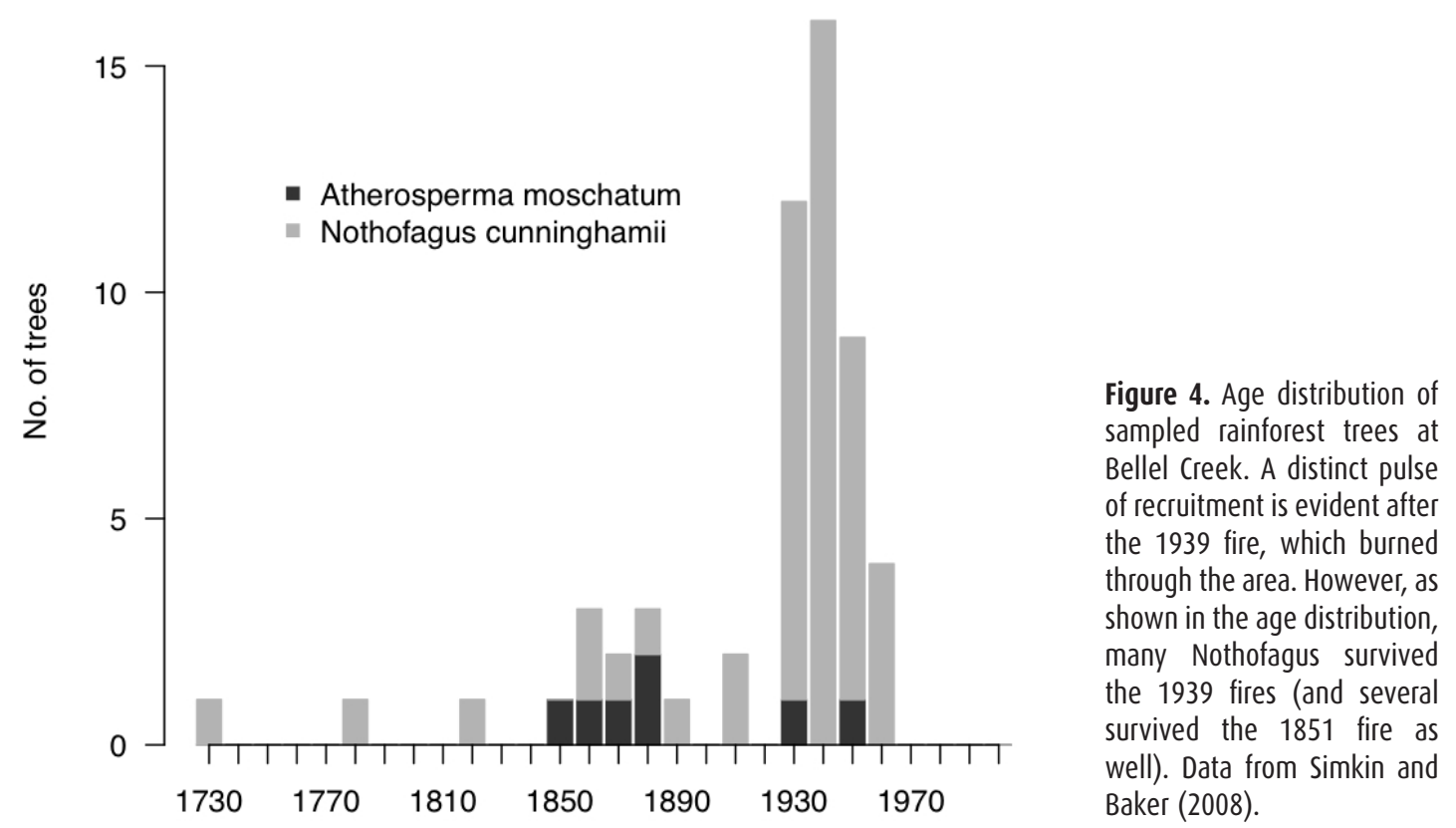

of several high-elevation $(>900 \mathrm{~m}$ ) sediment cores that have been dated to ca. $31,500 \mathrm{BP}$ and again from 20,000 BP, at which point the $N$. cunninghamii pollen are found continuously until the present, albeit with fluctuating abundance. The period 31,500-20,000 BP was during the last glacial, in which climatic conditions were as much as $5-8^{\circ} \mathrm{C}$ below current mean annual 
temperatures. At high-elevation sites in the Central Highlands, the vegetation would have been limited to either woodlands of extremely cold-tolerant eucalypts (e.g. E. pauciflora [snow gum]) or treeless alpine vegetation (e.g. tussock grasslands), both of which are evident in the pollen record from that period and both of which are found at much higher elevations today (e.g. above $1800 \mathrm{~m}$ on Mt Kosciuszko to the northeast).

The early Holocene is a period of rapid change in the pollen record from the Central Highlands (McKenzie 1997, 2002; McLeod 2007). At ca. 12,000 BP, treeline was near or below $900 \mathrm{~m}$ and wet sclerophyll and rainforest taxa were limited to low-elevation sites. By $9500 \mathrm{BP}$, herbaceous alpine taxa had retreated upwards across the Central Highlands and were limited to representation in only the highest elevation samples (McKenzie 2002). This change was accompanied by a rapid expansion of wet sclerophyll and rainforest taxa into higher elevation sites across the Central Highlands. During this period, $N$. cunninghamii pollen is a consistent component of the pollen record, but at sufficiently low levels to indicate that it was present but not particularly abundant. By ca. $6000 \mathrm{BP}, N$. cunninghamii reaches its highest representation in the pollen records across the entire elevational gradient of sites (168-1440 m) in the Central Highlands, including at the Bellel Creek site (McLeod 2007). However, fossil charcoal is found in all records from this period, suggesting that the likely warmer, moister climatic conditions of this 'forest optimum' (McKenzie 2002) did not eliminate the occurrence of fire within the landscape. Rather, fires were likely restricted to periods of anomalously dry climatic conditions that were too short to be recorded in the sedimentary record. From ca. $4500 \mathrm{BP}$, the abundance of pollen from $N$. cunninghamii and wet sclerophyll taxa decrease and charcoal levels increase, suggesting the onset of warmer, drier conditions. Kershaw et al. (2002) suggest that these changes were associated with a mid-Holocene strengthening of the El NinoSouthern Oscillation.

\section{Evidence from soil charcoal}

The pollen record suggests that the abundance of rainforest taxa in the Central Highlands has fluctuated over time. These changes in abundance are typically interpreted in terms of longterm climatic variability and, in particular, the role of climate on fire occurrence. Estimates of fire occurrence in the sediment cores come from measures of fine particulate charcoal, which may be produced locally or blown in from areas outside the catchment. As such, it is difficult to disentangle local and regional influences on the abundance of fine particulate charcoal measured in most sediment cores (Clark 1988). In contrast, macroscopic charcoal particles derived from partially combusted wood are almost exclusively local in origin. Because macro-charcoal may persist in the soil for tens of thousands of years, it can be used to reconstruct millennialscale variability in fire activity across relatively small areas. Stratigraphic analysis of charcoal within the soil profile, combined with radiocarbon dating, can be used together to develop a reconstruction of local fire activity at relatively coarse temporal scales. When compared with pollen records, which have similar dating resolution, soil charcoal records can provide a local context for interpreting the regional fire signal provided by the pollen and sediment records.

In the Central Highlands, McLeod (2007) used a network of soil pits at Bellel Creek to characterise the distribution and abundance of macro-charcoal particles in the forest soils for most of the past interglacial/glacial/interglacial cycle. Radiocarbon dating of the soil charcoal fragments revealed that fire activity at Bellel Creek has been highly variable since Oxygen Isotope Stage 3 (OIS3, ca. 50,000 BP, Figure 5). This variability is reflected in extended periods with little or no production of macro-charcoal fragments, punctuated by periods of extremely high macro-charcoal abundance. The three periods in which charcoal fragments were most abundant were 45,000-55,000 BP, 11,000-13,000 BP, and 0-2500 BP. Because the accuracy of radiocarbon dating decreases near the margins of prediction (ca. 45,000-50,000 BP), the 
errors associated with estimated ages are greatest for the oldest samples $(1 \sigma$ errors $=1700-3250$ calendar years). In contrast, the estimated ${ }^{14} \mathrm{C}$ dates from $0-15,000 \mathrm{BP}$ are all relatively tightly constrained ( $1 \sigma$ errors $=40-155$ calendar years $)$.

The most notable gap in the macro-charcoal record is from 13,000 BP to 38,000 BP, which is coincident with the Last Glacial Maximum (LGM) and the accompanying cooler, drier conditions. The pollen records from Bellel Creek and other sites within the Central Highlands suggest that during this period, the vegetation of the upper Central Highlands may have been largely treeless, with plants in the families Poaceae and Asteraceae dominating the vegetation (McKenzie 1997, 2002; McLeod 2007). Anatomical identification of the charcoal fragments found that $65 \%$ were from Eucalyptus spp., suggesting a forest composition similar to that which currently dominates most of the Central Highlands (Table 1; McLeod 2007). Notably, only 2\% of the charcoal fragments were attributed to Fagaceae (most likely Nothofagus cunninghamii) and all of these were restricted to the lower slope positions along the riparian margins.

The pulse of charcoal fragments at 11,000-13,000 BP occurs at the termination of the LGM, a period of rapid climatic and ecological changes across the region. Warming was occurring in the southwest Pacific as early as 17,000 BP (Turney et al. 2006), with markedly wetter conditions by 12,000-13,000 BP. Pollen from sediment cores collected above $900 \mathrm{~m}$ in the Central Highlands documents the transition from treeless alpine and sub-alpine vegetation to forest vegetation around this time (McKenzie 1997). The subsequent gap in soil charcoal fragments from 5000-11,000 BP is associated with forest expansion locally, regionally and globally, as the cool, dry conditions of the LGM ceded to the warmer, moister conditions of the early Holocene. Macro-charcoal fragments reappear at $4500 \mathrm{BP}$ and are found in great abundance from $2500 \mathrm{BP}$ to the present, suggesting a shift to a forested landscape in which fire was a more prominent disturbance or the vegetation was more flammable. As noted above, Kershaw et al. (2002) have proposed that this change was associated with a more general intensification of the El Nino-Southern Oscillation and its increasing influence on regional climate dynamics. The hotter, drier conditions would have increased the probability of fire occurrence and been more conducive to the successful establishment of eucalypts and other sclerophylous plant species.

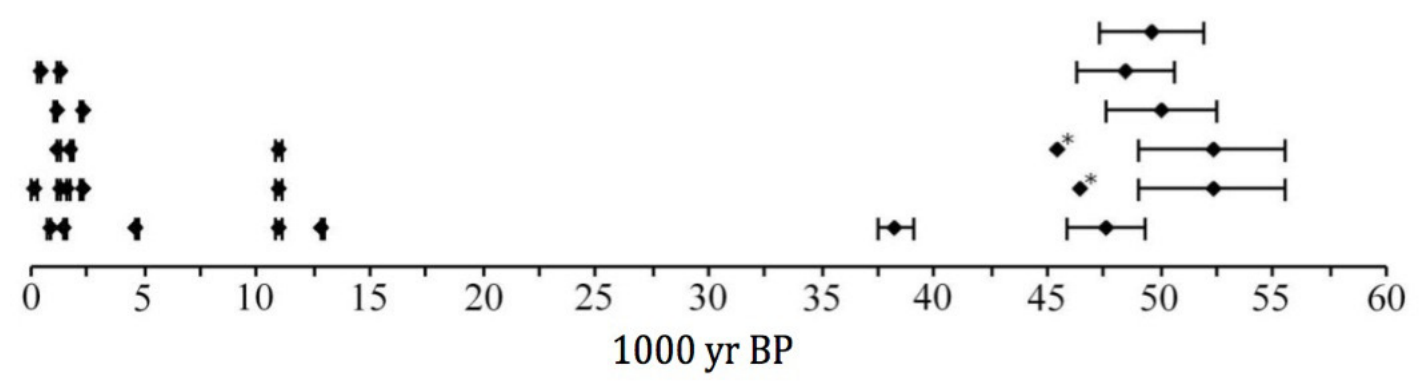

NB: $(*)$ indicates the lower limit of an infinite age, presented in ${ }^{14} \mathrm{C}$ years

Figure 5. Temporal spread of all AMS $14 \mathrm{C}$ dates on charcoal fragments obtained from Bellel Creek in the Central Highlands of Victoria. Data are presented in calendar years BP with 10 error bars. An asterisk (") indicates the lower limit of an infinite age. From McLeod (2007).

\section{So, how resilient is cool temperate rainforest to fire?}

The tree species that dominate Australian rainforests are generally considered to be sensitive to fire (e.g. Jackson 1968; Groves 1981; Bowman 2000, Figure 1), due to the absence or poor development of adaptations to fire, such as thick bark, vigorous epicormic sprouting and seritony, which are so well developed in most non-rainforest taxa (Gill and Ashton 1968; Gill 1981). Yet, across Australia areas of rainforest are commonly found within a matrix of fire-prone 
Table 1. Relative abundance of taxa at family level, grouped by slope position, from 476 soil charcoal fragments from Bellel Creek in the Central Highlands, Victoria. Species in the genera Eucalyptus and Nothofagus are in the families Myrtaceae and Fagaceae, respectively. From McLeod (2007).

\begin{tabular}{|c|c|c|c|}
\hline \multirow{2}{*}{ Family } & \multicolumn{3}{|c|}{ Slope position } \\
\hline & Upper & Middle & Lower \\
\hline Myrtaceae & 121 & 83 & 109 \\
\hline Leguminoseae & 42 & 7 & 17 \\
\hline Fagaceаe & 0 & 0 & 11 \\
\hline Other (incl. unidentified) & 21 & 15 & 50 \\
\hline Totals & 184 & 105 & 187 \\
\hline
\end{tabular}

sclerophyll vegetation, often dominated by Eucalyptus species. A range of hypotheses has been proposed to explain this pattern (see e.g. Bowman 2000). From first principles, however, the juxtaposition of fire-adapted sclerophyll forest and putatively fire-sensitive rainforest requires that at least one of the following hypotheses be true:

1. Fires do not transgress rainforest boundaries;

2. Rainforest species possess a degree of resilience to fire; and

3. Fire facilitates regeneration of rainforest species.

The cool temperate rainforests of the Central Highlands of southeastern Australia provide a unique opportunity to test these hypotheses for several reasons. First, cool temperate rainforest in the Central Highlands coexists with wet sclerophyll forest, where it typically occurs as scattered patches and strips within broad tracts of wet sclerophyll forest. Second, over the past two decades, palaeoecologists have developed multiple proxies - tree rings, soil charcoal and pollen - from the Central Highlands that provide a rich, multi-layered historical context for these forests that is not available in other regions of Australia. And third, in 2009 a major catastrophic fire event occurred, permitting direct observation of the impacts of an intense landscape-scale fire on cool temperate rainforest.

In the following sections, we consider the evidence for and against each of the three hypotheses described above. We focus particular attention on integrating the available palaeoproxy data with other sources of data on the contemporary ecology of the rainforest and wet sclerophyll forest taxa. We realise that these hypotheses are not mutually exclusive and that in some instances it will be difficult to differentiate one from the other given the available evidence. For example, if a fire does not burn a patch of rainforest, is that because the fire did not reach the rainforest or because the rainforest species are resilient to the fire and thus minimally affected? In addition, we realise that we may be accused of establishing 'straw man' hypotheses that can be easily knocked down. These are fair concerns, but we believe that the three hypotheses provide a coherent framework for identifying the impact of fire on cool temperate rainforest tree taxa and considering the implications for long-term forest dynamics, which is the basis of management and conservation of these unique ecosystems.

\section{Fires do not transgress rainforest boundaries}

If we accept the assumption that rainforest taxa are not well adapted to fires, then to persist within the landscape over long periods they must not be subjected to killing fires. That is, fires of some threshold level of intensity must not burn into the rainforest, otherwise widespread mortality would occur. The proxy records from the Central Highlands provide strong evidence that rainforest tree species and fire have been present together within the landscape for long 
periods. The pollen records indicate that the dominant rainforest tree species, $N$. cunninghamii, has been present within the landscape, albeit at varying abundance, for most of the past 30,000 years. The micro- and macro-charcoal record also indicates that fire has occurred over much of this period, with the most recent 2000 years showing the highest levels of fire in the proxy record. In addition to the proxy records of past fire occurrence across the Central Highlands landscape, historical records and direct observations provide further evidence of at least three major fires $(1851,1939$ and 2009) that have burned hundreds of thousands to millions of hectares of forests in the past 160 years.

Given these multiple, overlapping records of widespread fire throughout the Central Highlands over millennia, it is highly unlikely that areas bearing cool temperate rainforest would not have been directly impacted by fire. However, it is possible that they may have experienced less intense fires than the sclerophyll forest. Even within a landscape subjected to a catastrophic bushfire there is substantial variability in fire intensity at local scales (Figure 3). This variability derives from interactions among topography, microclimatic conditions, variability in weather conditions at the time of the fire (e.g. timing of wind changes, occurrence of rain), and the composition, structure and spatial arrangement of the vegetation. Cool temperate rainforest is often found in cool, moist gullies on southeastern-facing slopes where the lower temperatures and higher relative humidity provide a degree of microclimatic buffering from the fires. However, anecdotal observations from the 2009 bushfires indicate that the fireline intensities within the worst affected areas of the Central Highlands were in excess of $100,000-150,000 \mathrm{~kW} \mathrm{~m}^{-1}$. It seems unlikely that small differences in microclimatic conditions would have had much potential to stop the fires along the rainforest boundaries under such extreme conditions. However, they may have lowered the amount of radiant heat directed at the rainforest. Another factor that may reduce the intensity of fires burning into cool temperate rainforest is the difference in height of the dominant canopy trees in eucalypt forest and rainforest. In the wet sclerophyll forest, dominant $E$. regnans may be $70-80 \mathrm{~m}$ tall, whereas few $N$. cunninghamii reach more than $30 \mathrm{~m}$ in height. The preponderance of cool temperate rainforest trees in low-lying areas within the landscape (e.g. gullies and creek lines) further exacerbates differences in canopy height of the rainforest and wet sclerophyll forests. To burn the rainforest canopy, crown fires in the eucalypt forest matrix must drop a considerable distance. However, because heat energy is naturally displaced upwards, burning downwards occurs more slowly and with less energy. Thus, the rainforests may be exposed to less of the energy of the crown fires in the neighbouring tall eucalypt forest as they move towards the rainforest and confine the worst impacts of the fire to the margins of the rainforest. After the 2009 fires, Pappas (2010) found that of the 32 patches of burnt rainforest that she surveyed, the mean distance to the rainforest/eucalypt forest ecotone was only $2.5 \mathrm{~m}$ and was heavily skewed towards the edge of the rainforest. Only four patches were more than $15 \mathrm{~m}$ into the rainforest, and the one patch farthest into the interior of the rainforest ( $35 \mathrm{~m}$ from the edge) was found in a rainforest patch nearly $200 \mathrm{~m}$ wide.

\section{Rainforest species are resilient to fire}

The proxy data and direct observations suggest that as catastrophic crown fires race through a wet sclerophyll forest, the interdigitated rainforest patches are subjected to the radiant heat from the fire and may burn. If rainforest tree species have persisted within these landscapes under similar fire regimes over long periods, then they must be relatively resilient to fires. This may be manifest as either the ability to endure fires or the ability to regenerate in the wake of fires. In this section, we consider the potential of rainforest species to endure fire; in the next section, we consider the issue of fire-initiated regeneration in rainforest species.

The tree-ring records demonstrate that rainforest tree species can survive catastrophic fire 
events. At Bellel Creek in the Central Highlands, the 1939 fire killed eucalypts on both slopes above the creek, as well as rainforest trees within the riparian zone. Yet, a large number of rainforest trees (e.g. $N$. cunninghamii, A. moschatum ) that were alive at the time of sampling in 2006 were established well before the 1939 fire (Simkin and Baker 2008). In some cases, individual trees were $>200$ years old, indicating that they had survived both the 1851 and 1939 fires. Direct observations after the 2009 fire showed that the 2009 fires had generally burned up to the margins of the rainforest, but that along several hundred metres of the creek, small patches of rainforest (most $<200 \mathrm{~m}^{2}$ ) had been burned as well. The macro-charcoal record from Bellel Creek shows that fires have occurred within the boundaries of the extant cool temperate rainforest repeatedly over the past 2000 years. Obviously, then, some proportion of the populations of most rainforest taxa must be able to endure fires of moderate to high intensity.

The ability of any plant species to endure fires is highly dependent on the fuel characteristics or flammability of its foliage. Eucalypts are well known for their highly flammable foliage and the role of the volatile oils in their leaves in accelerating foliar combustion. Rainforest species have thicker leaves of higher moisture content and are thus likely to be less flammable (although there are few studies that have examined the flammability of rainforest species). Dickinson and Kirkpatrick (1985) showed that leaves of Atherosperma moschatum had lower energy content, had greater moisture and ash contents, and were much slower in propagating fire than eucalypt leaves. Importantly, they found that $A$. moschatum leaves would not ignite unless they had lost $>60 \%$ of their moisture content. In contrast, eucalypt and other 'dry' forest species would ignite when leaves had lost $<40-50 \%$ moisture content. We were unable to find equivalent data for the dominant rainforest canopy tree species $N$. cunninghamii, but would expect that the fuel properties of its leaves would be more similar to those of $A$. moschatum than those of eucalypts.

In crown fire ecosystems such as the mixed landscape of the Central Highlands, these differences in the foliar fuel properties of rainforest tree species may play a role in limiting the amount of fire damage to patches of rainforest. With fire spread rates of 5-10 $\mathrm{m}^{2} \mathrm{sec}^{-1}(20-40$ $\mathrm{km} \mathrm{hr}^{-1}$ ), the fire front may pass over the rainforest too quickly to both dry and ignite the foliar biomass in the canopy. In addition, because rainforest patches are often associated with riparian areas, the foliar moisture content of rainforest taxa may remain higher than in upland sites even during the extreme climatic conditions that precede major fire events, further buffering against initiation of crown fires within the rainforest.

The benefits of reduced foliar flammability do not confer immunity from fire, though. Where rainforest tree species are found as scattered individuals in upland sites, fire-induced mortality is much higher. In the 2009 fires, all individuals of $N$. cunninghamii occurring at low densities in the mid-storey of E. regnans stands or in narrow rainforest strips were killed. Rainforest taxa only survived where the width of the rainforest strip was $>50 \mathrm{~m}$ (Pappas 2010), suggesting that there is a threshold level of aggregation above which the benefits of higher foliar moisture content and reduced susceptibility to ignition of rainforest taxa would be able to modify fire behaviour. In large patches of cool temperate rainforest, the greatest heat loads from the adjacent eucalypt forest would only be experienced on the margins of the rainforest, meaning that the necessary pre-drying of the rainforest canopy foliage required for ignition would be less likely to occur in the interior of the rainforest patch. This was precisely what was observed in the 2009 fires. Even in areas of the landscape that experienced the most intense fires in 2009, the larger patches of rainforest survived, although they did not emerge unscathed from the fires. In most of these areas, the fires killed individual trees or small groups of trees, creating small to medium-sized gaps (median gap size ca. $1000 \mathrm{~m}^{2}$; range $160-26,000 \mathrm{~m}^{2}$ ) in the rainforest canopy and a rich ash bed on the forest floor. 


\section{Fire facilitates rainforest regeneration}

If fires burn into rainforest areas and the rainforest trees are killed, rainforest can still persist if the fire promotes the regeneration of the rainforest tree species. The conventional wisdom is that rainforest tree species, which typically have heavy, poorly dispersed seeds, do not regenerate well after fires. In mixed forest with a eucalypt overstorey and rainforest understorey, rainforest taxa are often overwhelmed by competition from the faster-growing eucalypt species. However, the tree-ring data demonstrate the ability of at least one rainforest canopy species to regenerate rapidly and profusely after a fire. At Bellel Creek, a pulse of $N$. cunninghamii regeneration established immediately after the 1939 fire, in both the riparian area dominated by cool temperate rainforest and the upland sites dominated by the tall eucalypts. Howard (1973) noted that the age structure of a large stand of N. cunninghamii on Mt Donna Buang in the Central Highlands was even-aged, suggesting mass recruitment in the wake of a large, stand-replacing disturbance (presumably fire). Silvicultural experiments in northwestern Tasmania that have manipulated overstorey density and forest floor conditions to evaluate the regeneration response of rainforest taxa support these observations. Hickey and Wilkinson (1999) showed that $N$. cunninghamii regeneration is most abundant and vigorous on sites in which most of the overstorey is removed and the ground is burned and/or mechanically disturbed. Indeed, seedlings in their clearfell (with standards) and burn treatment maintained height growth rates of ca. $45 \mathrm{~cm} \mathrm{yr}^{-1}$ over nearly two decades (Hickey and Wilkinson 1999). Ellis (1985) showed that after a fire in the 1850s in northeastern Tasmania, diameter growth rates of $N$. cunninghamii were similar to those of sympatric eucalypt species (ca. 3-4 $\mathrm{mm} \mathrm{yr}^{-1}$ ). In a selectively logged area of rainforest in western Tasmania, Jennings et al. (2005) found high levels of $N$. cunninghamii regeneration ( $>5000$ seedlings $\mathrm{ha}^{-1}$ ), but height growth rates were much slower (ca. $2.5 \mathrm{~cm} \mathrm{yr}^{-1}$ ), although this has been attributed in part to the thin, peaty soils at the site. There was no evidence of $A$. moschatum recruitment despite the presence of adults in the pre-logging rainforest.

In general, the seeds of the dominant tree species in the cool temperate rainforest are relatively large and are dispersed by gravity, water or animals (Howard 1973). In addition, $N$. cunninghamii, like many Fagaceae, is a mast-fruiting tree species, producing large fruit crops at irregular, supra-annual intervals (Howard 1973; Hickey and Wilkinson 1999). In landscapes subjected to rare, but catastrophic, bushfires, mast fruiting would appear to present a serious risk. If mast fruiting occurs in the year or two before a fire, the trees may not have the reproductive capacity to take advantage of the regeneration opportunity presented by a disturbance. However, despite this, $N$. cunninghamii is one of the two dominant canopy tree species in cool temperate rainforest in the Central Highlands and has been for nearly 30,000 years.

Pappas (2010) also noted that almost all of the $N$. cunninghamii that were partially damaged in the 2009 fires showed evidence of vegetation regeneration. Individuals that suffered crown scorch were producing sprouts at the base of the scorched branches, while individuals that suffered heat damage to the main stem were sprouting from the base of the tree. This rapid re-establishment of photosynthetic cover by the rainforest species, independent of sexual reproduction, may be an important mechanism in allowing rainforest taxa to persist in these landscapes where fires are rare, but intense and often damaging (Bond and Midgley 2001).

\section{Conclusion}

Cool temperate rainforest and fires have coexisted in the Central Highlands for much of the past 40,000 years. In the past 2500 years, fire activity has been as high or higher than at any other time in the past 40,000 years, yet rainforest is still relatively common across the landscape. Evidence from multiple, overlapping palaeo-proxies, as well as direct observations 
after the 2009 fires, suggests that the high-intensity crown fires that burn across the Central Highlands once or twice each century do reach into patches of rainforest, but that many of the rainforest tree species are capable of withstanding the impacts of these fires and, at least in the case of N. cunningbamii, can quickly respond with increased recruitment soon after the fire has passed. Direct observations demonstrate that patches of rainforest do survive extreme fires; tree rings covering several centuries show that rainforest trees have survived previous fires and that they are capable of recruiting immediately after large fires. The charcoal and pollen evidence, which cover at least 40,000 years, indicate that the cool temperate rainforests of the Central Highlands have survived major fires over that period. Although the dominant tree species in the cool temperate rainforests are not as highly adapted to fire as the tall eucalypts in the adjacent wet sclerophyll forest, they appear to be more resilient to fire than widely believed. This resilience derives from interactions among the nature of the environment in which the taxa typically occur, their reproductive behaviour in relation to fire, the flammability of their foliage and, finally, stand- and landscape-scale heterogeneity in fire intensity.

\section{References}

Allen, K.J., Cook, E.R., Francey, R.J. and Michael, K. 2001. The climatic response of Phyllocladus aspleniifolius (Labill.) Hook. $\mathrm{f}$ in Tasmania. Journal of Biogeography 28:305-316.

Allen, K.J., Ogden, J., Buckley, B.M., Cook, E.R. and Baker, P.J. In press. The potential to reconstruct broadscale climate indices associated with southeast Australian droughts from Athrotaxis species, Tasmania. Climate Dynamics.

Ash, J. 1988. The location and stability of rainforest boundaries in north-eastern Queensland, Australia. Journal of Biogeography 15:619-630.

Ashton, D. 2000. The Big Ash forest, Wallaby Creek, Victoria - changes during one lifetime. Australian Journal of Botany 48:1-26.

Attiwill, P.M. 1994. Ecological disturbance and the conservative management of eucalypt forests in Australia. Forest Ecology and Management 63:301-346.

Bond, W.J. and Midgley, J.J. 2001. Ecology of sprouting in woody plants: The persistence niche. Trends in Ecology and Evolution 16:45-51.

Bowman, D. 2000. Australian Rainforests: Islands of Green in a Land of Fire. Cambridge: Cambridge University Press.

Brown, P.M. and Wu, R. 2005. Climate and disturbance forcing of episodic tree recruitment in a southwestern ponderosa pine landscape. Ecology 86:3030-3038.

Busby, J.R. and Brown, M.J. 1994. Southern rainforests. In: Groves R.H. (ed), Australian Vegetation (second ed.), pp. 131-155. Cambridge: Cambridge University Press.

Clark, J.S. 1988. Particle motion and the theory of charcoal analysis: source area, transport, deposition, and sampling. Quaternary Research 30:81-91.

Cook, E.R., Bird,T., Peterson, M., Barbetti, M., Buckley, B., D’Arrigo, R., Francey, R. and Tans, P. 1991. Climatic change in Tasmania inferred from a 1089-year tree-ring chronology of Huon Pine. Science 253:1266-1268.

Cook, E.R., Buckley, B., D’Arrigo, R. and Peterson, M. 2000. Warm-season temperatures since $1600 \mathrm{BC}$ reconstructed from Tasmanian tree rings and their relationship to large-scale sea surface temperature anomalies. Climate Dynamics 16:79-91.

Dickinson, K.J.M. and Kirkpatrick, J.B. 1985. The flammability and energy content of some important plant species and fuel components in the forests of southeastern Tasmania. Journal of Biogeography 12:121-134.

Donato, D.C., Fontaine, J.B., Campbell, J.L., Robinson, W.D., Kauffman, J.B. and Law, B.E. 2009. Conifer regeneration in stand-replacement portions of a large mixed-severity wildfire 
in the Klamath-Siskiyou Mountains. Canadian Journal of Forest Research 39:823-838.

Ellis, R. 1985. The relationships among eucalypt forest, grassland and rainforest in a highland area in north-eastern Tasmania. Australian Journal of Ecology 10(3):297-314.

Gill, A.M. 1981. Adaptive responses of Australian vascular plant species to fires. In: Gill, A.M., Groves, R.H., and Noble, I.R. (eds), Fire and the Australian Biota, pp. 243-272. Australian Academy of Science, Canberrra.

Gill, A.M. and Ashton, D.H. 1968. The role of bark type in relative tolerance to fire of three central Victorian eucalypts. Australian Journal of Botany 16:491-498.

Groves, R.H. 1981. Australian Vegetation. Cambridge University Press: Cambridge, UK.

Hickey, J.E. and Wilkinson, G.R. 1999. Long-term regeneration trends from a silivicultural systems trial in lowland cool temperate rainforest in Tasmania. TasForests 11:1-22.

Hill, R. and Read, J. 1984. Post-fire regeneration of rainforest and mixed forest in western Tasmania. Australian Journal of Botany 32:481-493.

Hill, R.S.2000. Attempting to define the impossible: a commentary on 'Australian Rain-forests: Islands of Green in a Land of Fire'. Australian Geographical Studies 38:320-326.

Howard,T.1973.Studies in the ecology of Nothofagus cunninghamii Oerst.I.Natural regeneration on the Mt. Donna Buang massif, Victoria. Australian Journal of Botany 21:67-78.

Jackson, W.D. 1968. Fire, air, water, and earth - an elemental ecology of Tasmania. Proceedings of Ecological Society of Australia 3:9-16.

Jennings, S., Edwards, L.G. and Hickey, J.E. 2005. Natural and planted regeneration of huon pine (Lagarostrobus franklinii) at Travellers Creek, western Tasmania. TasForests 16:61-70.

Kashian, D.M., Tinker, D.B., Turner, M.G. and Scarpace, F.L. 2004. Spatial heterogeneity of lodgepole pine sapling densities following the 1988 fires in Yellowstone National Park, Wyoming, USA. Canadian Journal of Forest Research 34:2263-2276.

Kershaw, A.P., Clark,J.S., Gill, A.M. and D'Costa, D.M. 2002. A history of fire in Australia.In: Bradstock, R.A., Williams, J.E. and Gill, A.M.(eds), Flammable Australia: The Fire Regimes and Biodiversity of a Continent, pp. 3-25. Cambridge: Cambridge University Press.

Lindenmayer, D.B., Mackey, B., Cunningham, R., Donnelly, C., Mullen, I., McCarthy, M.A. and Gill, A.M. 2000. Factors affecting the presence of the cool temperate rain forest tree myrtle beech (Nothofagus cunninghamii) in southern Australia: integrating climatic, terrain and disturbance predictors of distribution patterns. Journal of Biogeography 27:1001-1009.

McKenzie, G.M. 1997. The late quaternary vegetation history of the south-central highlands of Victoria, Australia. I. Sites above 900 m. Austral Ecology 22:19-36.

McKenzie, G.M. 2002. The late Quaternary vegetation history of the south-central highlands of Victoria, Australia. II. Sites below 900 m. Austral Ecology 27:32-54.

McLeod, A.J. 2007. Palaeoenvironmental change in the Central Highlands of Victoria, Australia, interpreted from the analysis of macroscopic soil charcoal. Unpublished $\mathrm{PhD}$ thesis, Monash University.

Noble, I.R. and Slatyer, R.O. 1980. The use of vital attributes to predict successional changes in plant communities subject to recurrent disturbances. Plant Ecology 43:5-21.

Oliver, C.D., Larson, B.C. 1996. Forest Stand Dynamics. New York: John Wiley and Sons.

Pappas, N. 2010. The impacts of the 2009 bushfires on cool temperate rainforest in the Central Highlands of Victoria. Unpublished BSc (Honours) thesis, Monash University.

Read, J. and Hill, R. 1985. Dynamics of Nothofagus-dominated rainforest on mainland Australia and lowland Tasmania. Plant Ecology 63:67-78.

Schoennagel, T., Smithwick, E.H. and Turner, M.G. 2008. Landscape heterogeneity following large fires: insights from Yellowstone National Park, USA. International Journal of Wildland Fire 17:742-753.

Simkin, R. and Baker, P.J. 2008. Disturbance history and stand dynamics in tall open forest and 
riparian rainforest in the Central Highlands of Victoria. Austral Ecology 33:747-760.

Sniderman, J.M.K., Porch, N. and Kershaw, A.P. 2009. Quantitative reconstructions of Early Pleistocene climate in southeastern Australia and implications for atmospheric circulation. Quaternary Science Reviews 28:3185-3196.

Swetnam, T.W. 1993. Fire history and climate change in giant sequoia groves. Science 262:885889.

Swetnam, T.W. and Betancourt, J.L. 1990. Fire-southern oscillation relations in southwestern United States. Science 249:1017-1020.

Turney, C.S.M., Kershaw, A.P., Lowe, J.J., van der Kaars, S., Johnston, R., Rule, S., Moss, P., Radke, L., Tibby, J., McGlone, M.S., Wilmshurst, J.M., Vandergoes, M.J., Fitzsimons, S.J., Bryant, C., James, S., Branch, N.P., Comely, J., Kalin, R.M., Ogle, N., Jacobson, G. and Fifield, L.K. 2006. Climatic variability in the southwest Pacific during the Last Termination (20-10 kyr BP). Quaternary Science Revierws 25:886-903.

Unwin, G.L. 1989. Structure and composition of the abrupt rainforest boundary in the Herberton Highland, North Queensland. Australian Journal of Botany 37:413-428.

Whitlock, C., Bartlein, P., Marlon, J., Brunelle, A. and Long, C. 2003. Holocene fire reconstructions from the northwestern US: an examination at multiple time scales. Fifth Symposium on Fire and Forest Meteorology American Meteorological Society.

Whitlock, C., Skinner, C.N., Bartlein, P.J., Minckley, T. and Mohr, J.A. 2004. Comparison of charcoal and tree-ring records of recent fires in the eastern Klamath Mountains, California, USA. Canadian Journal of Forest Research 34:2110-2121. 